\title{
Modified technique for Melody valve implantation in the mitral position
}

\author{
Nathaniel B. Langer, MD, MSc, ${ }^{\mathrm{a}}$ David Solowiejczyk, MD, ${ }^{\mathrm{b}}$ John T. Fahey, MD, ${ }^{\mathrm{c}}$ Alejandro Torres, MD, ${ }^{\mathrm{b}}$ \\ Emile Bacha, MD, ${ }^{a}$ and David Kalfa, MD, PhD, ${ }^{a}$ New York, NY, and New Haven, Conn
}

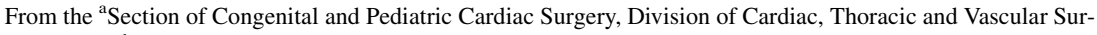
gery, and ${ }^{\mathrm{b}}$ Division of Pediatric Cardiology, Morgan Stanley Children's Hospital, NewYork-Presbyterian Hospital/Columbia University Medical Center, New York, NY; and ${ }^{\mathrm{c}}$ Department of Pediatrics, Section of Pediatric Cardiology, Yale School of Medicine, New Haven, Conn.

No funding was provided to support this work.

Disclosures: A.T. is a proctor for Edwards Sapien transcatheter valves. All other authors have nothing to disclose with regard to commercial support.

Received for publication Jan 7, 2018; revisions received March 29, 2018; accepted for publication April 3, 2018; available ahead of print April 27, 2018.

Address for reprints: David Kalfa, MD, PhD, Morgan Stanley Children's Hospital, NewYork-Presbyterian Hospital/Columbia University Medical Center, 3959 Broadway, New York, NY 10032 (E-mail: dk2757@cumc. columbia.edu)

J Thorac Cardiovasc Surg 2018;156:1190-1

$0022-5223 / \$ 36.00$

Copyright (c) 2018 by The American Association for Thoracic Surgery

https://doi.org/10.1016/j.jtcvs.2018.04.001
}

Surgical options for children with irreparable mitral valve (MV) disease are limited, consisting primarily of fixeddiameter valves or homografts that cannot grow, have poor longevity, or require anticoagulation. To avoid these problems, multiple groups have reported surgically implanting transcatheter valves in the mitral position. ${ }^{1-4}$ The most widely used is the Melody valve (Medtronic Inc, Parsippany, NJ), a stented, valved bovine jugular vein graft. Because of its design, specifically its length, the Melody valve presents unique challenges when used for MV replacement, including left ventricular outflow tract (LVOT) and pulmonary vein (PV) obstruction. We present a modified technique for Melody valve implantation in the mitral position that simplifies previous techniques and minimizes these complications.

\section{SURGICAL TECHNIQUE}

We implanted 4 Melody valves with the distal stent fixed to the mitral annulus and the remainder of the device within the left atrium (Figure 1). To do this, the proximal and distal portions of the stent are folded to achieve a device length of 18 to $20 \mathrm{~mm}$. With interrupted sutures, a CorMatrix (Aziyo Biologics, Silver Spring, Md) or Cardiocel (Admedus, Eagan, Minn) skirt is secured to the distal end of the stent as a sewing cuff, taking care not to injure the leaflets. The patient's left atrium is opened through the Sondergaard groove, and the MV and subvalvular apparatus are resected. Then 5-0 polypropylene, nonpledgeted mattress sutures are passed through the mitral annulus and the sewing cuff, taking care not to catch any component of the valve apparatus. The valve is then partially expanded, tied in place, and balloon dilated to the desired final diameter. This is determined by adding $3 \mathrm{~mm}$ to the native valve annular diameter, as measured intraoperatively with Amato dilators. Potential

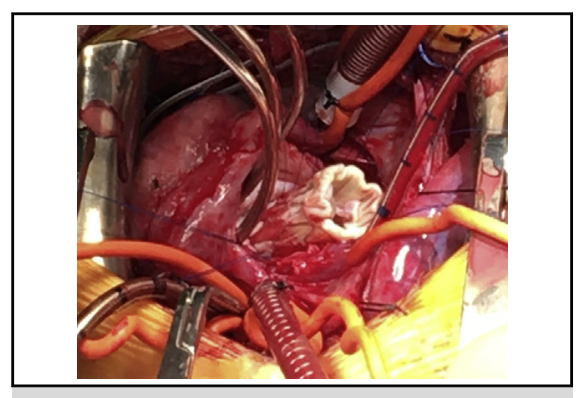

"High-riding" Melody valve with folded ends and distal end affixed to the mitral annulus.

Central Message

Mitral valve replacement with a Melody valve has unique advantages and technical challenges. We present a simplified technique that minimizes the risk of outflow tract or pulmonary vein obstruction.

See Editorial Commentary page 1192.

PV obstruction is avoided by augmenting the left atrium with CorMatrix or Cardiocel. Finally, we create a small atrial septal defect, as posterior as possible, to allow percutaneous balloon dilation of the valve.

\section{CLINICAL SUMMARY}

Patient characteristics are presented in Table 1. All patients underwent MV replacement as described. There were no instances of significant paravalvular leakage, nor

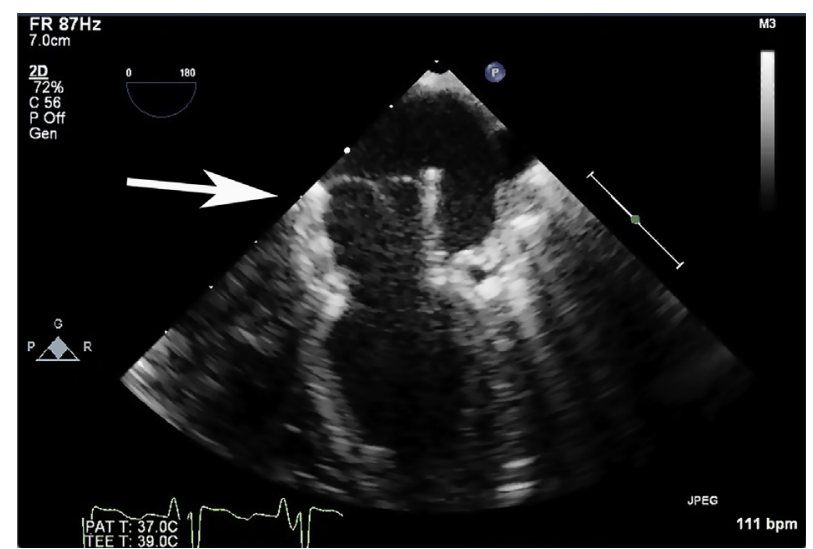

FIGURE 1. Transesophageal echocardiogram of a "high-riding" Melody valve in the mitral position. Arrow highlights valve prosthes. 


\begin{tabular}{|c|c|c|c|c|c|c|c|c|c|c|c|}
\hline Case & Sex & $\begin{array}{l}\text { Age } \\
(\mathbf{m o})\end{array}$ & $\begin{array}{c}\text { Weight } \\
(\mathbf{k g})\end{array}$ & Surgical indication & Prior operations & $\begin{array}{l}\text { CPB } \\
\text { time } \\
(\mathbf{m i n}) \\
\end{array}$ & $\begin{array}{c}\mathrm{XC} \\
\text { time } \\
(\mathrm{min}) \\
\end{array}$ & $\begin{array}{c}\begin{array}{c}\text { Final } \\
\text { valve } \\
\text { diameter } \\
(\mathbf{m m})\end{array} \\
\end{array}$ & $\begin{array}{c}\text { Paravalvular } \\
\text { leak }\end{array}$ & $\begin{array}{c}\text { Transvalvular } \\
\text { gradient } \\
\text { (mm Hg) }\end{array}$ & $\begin{array}{c}\text { Central } \\
\text { mitral } \\
\text { regurgitation }\end{array}$ \\
\hline 1 & $\mathrm{M}$ & 2 & 5.6 & $\begin{array}{l}\text { Arcade MV, } \\
\text { moderate MR, } \\
\text { severe MS }\end{array}$ & MV repair & 102 & 73 & 16 & None & 6 & Trace-mild \\
\hline 2 & M & 12 & 7.3 & $\begin{array}{l}\text { Shone complex, } \\
\text { severe MR/MS }\end{array}$ & $\begin{array}{l}\text { Stage I palliation } \\
\text { with RV-PA conduit, } \\
\text { DKS takedown with } \\
\text { Ross-Konno and } \\
\text { MV plasty }\end{array}$ & 107 & 73 & 18 & None & 3.5 & Mild \\
\hline 3 & M & 4 & 5.5 & $\begin{array}{c}\text { Dysplastic MV, } \\
\text { severe MR }\end{array}$ & None & 189 & 137 & 18 & None & 6 & Mild \\
\hline 4 & M & 28 & 13.2 & $\begin{array}{l}\text { Shone complex, } \\
\text { severe MR/MS }\end{array}$ & $\begin{array}{l}\text { MV repair + aortic } \\
\text { arch plasty }\end{array}$ & 98 & 72 & 20 & None & 4 & None \\
\hline
\end{tabular}

Reported transvalvular gradients and degree of central mitral regurgitation are from each patient's most recent follow-up echocardiogram. $C P B$, Cardiopulmonary bypass; $X C$, aortic crossclamp; $M V$, mitral valve; $M R$, mitral regurgitation; $M S$, mitral stenosis; $R V$, right ventricle; $P A$, pulmonary artery; $D K S$, Damus-Kaye-Stansel.

any of LVOT or PV obstruction. All patients were given daily aspirin on postoperative day 1 , which continued after discharge. Patient 1 required slow weaning from inotropic support and inhaled nitric oxide as a result of severe preoperative pulmonary hypertension but was successfully discharged home on room air on postoperative day 25 . Patients 2, 3, and 4 were discharged home without supplemental oxygen after uneventful postoperative courses on postoperative days 17, 10, and 10, respectively. After 6, 5, 2 , and 1 months, for patients 1 through 4 respectively, follow-up echocardiograms showed no significant change in valve function.

\section{DISCUSSION}

In children who require MV replacement, the Melody valve is an attractive option because of the potential for balloon expansion during childhood growth and the avoidance of anticoagulation. This valve can obstruct the LVOT or PVs, however, especially in small children or those with small cardiac chambers. Here we report a modified procedure that we believe is applicable to all patients because of several important differences from previously described techniques. In their reports, the Boston group avoided LVOT obstruction by suturing the distal stent to the posterior left ventricular wall, trimming the crown of the device, or incising the LVOT-facing valve sinus. ${ }^{2,5}$ Although effective, these steps complicate valve implantation and carry potential dangers, including suture rupture with subsequent LVOT obstruction and damage to the Melody device. For all patients, regardless of chamber size, we shorten the device by folding the stent, which is effective and avoids potential valve damage. ${ }^{3}$ Furthermore, by implanting the device entirely within the left atrium, we avoid LVOT obstruction. This "high-riding" implantation has not caused significant movement of the prosthesis during the cardiac cycle or any significant paravalvular leakage. Patch augmentation of the left atrium is technically straightforward and prevents obstruction of valve inflow by the atrial wall or PV obstruction by the valve itself, so we believe that this technique is applicable even in patients with small left-sided chambers. We have not yet, however, used this technique in a neonate with a purely stenotic MV and small left atrium. Long-term follow-up is warranted to assess the impact of this "high-riding" implantation on the potential for further transcatheter balloon dilation.

\section{CONCLUSIONS}

A "high-riding" implantation of the Melody valve, along with left atrial patch augmentation, preserves the important advantages of the Melody valve in the mitral position while simplifying the overall procedure and avoiding potential LVOT and PV obstruction. This modified technique is an additional option for surgeons when faced with the challenge of MV replacement in small children.

\section{References}

1. Emani SM. Melody valve for mitral valve replacement. Oper Tech Thorac Cardiovasc Surg. 2014;19:454-63.

2. Abdullah I, Ramirez FB, McElhinney DB, Lock JE, del Nido PJ, Emani S. Modification of a stented bovine jugular vein conduit (melody valve) for surgical mitral valve replacement. Ann Thorac Surg. 2012;94:e97-8.

3. Hofmann M, Dave H, Hübler M, Kretschmar O. Simplified surgical-hybrid Melody ${ }^{\circledR}$ valve implantation for paediatric mitral valve disease. Eur J Cardiothorac Surg. 2015;47:926-8.

4. Chai PJ, George I, Nazif TM, Kalfa DM, Kodali SK, Torres AJ, et al. Use of stented bovine pericardial valve for surgical mitral valve replacement in infants. J Thorac Cardiovasc Surg. 2016;151:e51-2.

5. Quiñonez LG, Breitbart R, Tworetsky W, Lock JE, Marshall AC, Emani SM Stented bovine jugular vein graft (Melody valve) for surgical mitral valve replacement in infants and children. J Thorac Cardiovasc Surg. 2014;148:1443-9. 